\title{
si-RNA inhibition of brain insulin or insulin-like growth factor receptors causes developmental cerebellar abnormalities: relevance to fetal alcohol spectrum disorder
}

\author{
Suzanne M de la Monte $1,2,3,4,5,6^{*}$, Ming Tong ${ }^{4,5}$, Nathaniel Bowling ${ }^{5}$ and Peter Moskal ${ }^{5}$
}

\begin{abstract}
Background: In experimental models of fetal alcohol spectrum disorder (FASD), cerebellar hypoplasia and hypofoliation are associated with insulin and insulin-like growth factor (IGF) resistance with impaired signaling through pathways that mediate growth, survival, plasticity, metabolism, and neurotransmitter function. To more directly assess the roles of impaired insulin and IGF signaling during brain development, we administered intracerebroventricular (ICV) injections of si-RNA targeting the insulin receptor, (InR), IGF-1 receptor (IGF-1R), or IGF-2R into postnatal day 2 (P2) Long Evans rat pups and examined the sustained effects on cerebellar function, structure, and neurotransmitter-related gene expression (P20).

Results: Rotarod tests on P20 demonstrated significant impairments in motor function, and histological studies revealed pronounced cerebellar hypotrophy, hypoplasia, and hypofoliation in si-InR, si-IGF-1R, and si-IGF-2R treated rats. Quantitative RT-PCR analysis showed that si-InR, and to a lesser extent si-IGF-2R, broadly inhibited expression of insulin and IGF-2 polypeptides, and insulin, IGF-1, and IGF-2 receptors in the brain. ELISA studies showed that si-InR increased cerebellar levels of tau, phospho-tau and $\beta$-actin, and inhibited GAPDH. In addition, si-InR, si-IGF-1R, and si-IGF-2R inhibited expression of choline acetyltransferase, which mediates motor function. Although the ICV si-RNA treatments generally spared the neurotrophin and neurotrophin receptor expression, si-InR and si-IGF-1R inhibited NT3, while si-IGF-1R suppressed BDNF.

Conclusions: early postnatal inhibition of brain InR expression, and to lesser extents, IGF-R, causes structural and functional abnormalities that resemble effects of FASD. The findings suggest that major abnormalities in brains with FASD are mediated by impairments in insulin/IGF signaling. Potential therapeutic strategies to reduce the long-term impact of prenatal alcohol exposure may include treatment with agents that restore brain insulin and IGF responsiveness.
\end{abstract}

\section{Background}

In the central nervous system (CNS), insulin and insulin-like growth factors (IGFs) transmit pro-growth and pro-survival signals by activating complex intracellular pathways, beginning with ligand binding to cell surface receptors. Activated receptor tyrosine kinases phosphorylate insulin receptor substrate (IRS) proteins [1], which then interact with $\operatorname{src}$ homology domain-containing

\footnotetext{
* Correspondence: Suzanne_delamonte_md@Brown.edu 'Department of Pathology and Division of Neuropathology, Rhode Island Hospital, 593 Eddy Street, Providence, RI 02903 USA

Full list of author information is available at the end of the article
}

adaptor molecules to promote mitogenesis, cell survival, gene expression, metabolism, and motility [1-3]. Insulin, IGF-1 and IGF-2, and their corresponding receptors are abundantly expressed in neurons $[1,4,5]$ and glia [6-8] throughout the brain, but the highest levels are distributed in the hypothalamus, temporal lobe, and cerebellum [1], i.e. major targets of ethanol-mediated neurotoxicity. Given that insulin and IGF mediate neuronal survival, plasticity, energy metabolism, and neurotransmitter function [1,9-12], we hypothesized that sustained impairments in these signaling pathways would have dire consequences with respect to CNS function.

\section{C) Biomed Central}


During development, the brain is a major target of alcohol-mediated toxicity and teratogenesis. The constellation of neurodevelopmental and behavioral abnormalities caused by chronic gestational exposure to alcohol is termed, "fetal alcohol spectrum disorder" (FASD) [13-19]. In the cerebellum, effects of FASD include hypoplasia, hypo-foliation, reduced neuronal survival, disordered cell migration, and impaired motor function [15-17,20-22]. There is now sufficient evidence that many of these adverse effects of ethanol are mediated by impairments in insulin and IGF signaling [22-27]. Ethanol impairs insulin and IGF signaling in immature neuronal cells [28] by reducing ligandreceptor binding, and inhibiting receptor tyrosine kinase activation of downstream pathways through IRS [22-27]. Consequences include, down-regulation of insulin/IGF responsive genes $[22,24,26,29,30]$, increased oxidative stress, DNA damage, lipid peroxidation, and mitochondrial dysfunction [24,25,31,32], and reduced neuronal survival, plasticity [24,32,33], energy metabolism, and choline acetyltransferase (ChAT) activity [22,25,27,34]. ChAT is a major neurotransmitter that is needed for cognitive and motor functions [35-38].

The present study examines the degree to which inhibition of insulin/IGF signaling through their corresponding receptors is sufficient to mimic ethanolimpaired cerebellar development and function. We utilized an in vivo model in which insulin or IGF receptor genes were inhibited in rat pup brains by intracerebroventricular (ICV) delivery of si-RNA duplexes targeting the insulin receptor (si-InR), IGF-1 receptor (si-IGF-1R), or IGF-2 receptor (si-IGF-2R), or nonspecific sequences (si-Scr) $[39,40]$, and examined the sustained effects of these si-RNA treatments on motor function, cerebellar structure, and neurotransmitter and neurotrophin gene expression. The cerebellum was the focus of our investigations because: 1 ) it develops mainly in the early postnatal period; 2) it is one of the primary targets of ethanol-mediated neurotoxicity (other sites include the hippocampus, corpus callosum, cerebral cortex, and caudate nucleus); and 3) it expresses abundant levels of insulin and IGF receptors during development $[1,20,22,27,41-43]$.

\section{Methods \\ Materials}

Qiazol reagent, EZ1 RNA universal tissue kit, QuantiTect SYBR Green polymerase chain reaction (PCR) master mix, and the BIO Robot Z1 were from Qiagen Inc (Valencia, CA). Monoclonal antibodies to $\beta$-Actin, tau, phospho-tau (AT8-S199, S202, T205), brain-derived neurotrophic factor (BDNF), nerve growth factor (NGF), neurotrophin 3 (NT3), neurotrophin 4 (NT4), glyceraldehyde-3-phosphate dehydrogenase (GAPDH), choline acetyltransferase (ChAT), acetylcholinesterase (AChE), and 4-hydroxy-2-nonenal (HNE) were purchased from Abcam Inc. (Cambridge, MA), Santa Cruz Biotechnology Inc. (Santa Cruz, CA), or Chemicon International (Tecumsula, CA). The 85G6 aspartyl-(asparaginyl)- $\beta$ hydroxylase $(\mathrm{AAH})$ monoclonal antibody was generated to human recombinant protein and purified over Protein G columns (Healthcare, Piscataway, NJ) [44]. Small interfering RNA duplex molecules and Dharmafect reagent were purchased from Dharmacon, Inc. (Chicago, IL). Histofix was purchased from Histochoice (Amresco, Solon, $\mathrm{OH}$ ). The AMV first strand cDNA synthesis kit was obtained from Roche Diagnostics Corporation (Indianapolis, IN). Diaminobenzidine (DAB) chromogen was from Vector Laboratories (Burlingame, CA). PCR primers were purchased from Sigma Chemical Co. (St. Louis, MO). Enzyme-linked immunosorbant assay (ELISA) 96-well plates and the ELISA plate washer were from Nunc (Rochester, NY). Horseradish peroxidase (HRP)-conjugated secondary antibody and Amplex Red soluble fluorophore were from Invitrogen (Carlsbad, CA). HRP-labeled polymer conjugated secondary antibody used for immunohistochemistry was purchased from Dako Corp (Carpinteria, CA). The SpectraMax M5 microplate reader was purchased from Molecular Devices Corp. (Sunnyvale, CA). NanoOrange and the bicinchoninic acid (BCA) assay reagents were from Pierce chemical Corp. (Rockford, IL). All other fine chemicals were purchased from CalBiochem (Carlsbad, CA), Pierce (Rockford, IL), or Sigma (St. Louis, MO).

\section{Gene Delivery Model}

Postnatal day 2 (P2) Long Evans rat pups were given a single intracerebroventricular (ICV) injection of small interfering RNA duplexes (si-RNA) targeting the insulin receptor (si-InR) [INSR NM_017071], IGF-1 receptor (si-IGF-1R) [IGF1R NM_052807], IGF-2R (si-IGF-2R) [IGF2R NM_012756], or nonspecific sequences (Scrambled; si-Scr) [NM D-001210-01-20]. For each rat, $0.4 \mathrm{nmol}$ si-RNA plus $100 \mathrm{ng}$ recombinant green fluorescent protein (GFP) expressing plasmid were complexed with $10 \mu \mathrm{l}$ of Dharmafect reagent, and injected into the right frontal region over the lateral ventricle using a Hamilton syringe with a 26-gauge needle as previously described $[39,40]$. GFP expression, which was under the control of a CMV promoter [45], was used to monitor success of transfection. This was accomplished by sacrificing rats $(\mathrm{N}=4$ per group) at regular intervals after the ICV gene delivery, and measuring GFP mRNA levels in whole brain homogenates by qRT-PCR analysis. Those studies demonstrated peak levels of GFP expression within 2-3 days after ICV gene delivery, followed by a gradual decline in GFP expression. Importantly, GFP expression persisted over the time course of the 
experiment, consistent with findings in previous studies [39]. All rats survived the procedure, and none exhibited adverse responses such as, failure to thrive, poor grooming, reduced physical activity, or weight loss.

Gene expression and histological studies pertaining to the effects of si-InR, si-IGF-1R, or si-IGF-2R were performed with cerebella harvested on P24. Upon sacrifice, freshly harvested cerebella were divided in the midsagittal plane. One hemisphere was immersion fixed in Histofix, and the other was snap-frozen in a dry ice/ methanol bath and stored at $-80^{\circ} \mathrm{C}$ for mRNA and protein studies. The fixed tissue was embedded in paraffin and used to generate hematoxylin and eosin (H\&E) stained histological sections ( $5 \mu$ m-thick). In addition, adjacent sections were immunostained with monoclonal antibodies to 4-hydroxy-2-nonenal (HNE) or aspartyl-(asparaginyl)- $\beta$-hydroxylase (AAH), as previously described [44], except that immunoreactivity was detected with HRP-labeled polymer-conjugated secondary antibody and DAB. The sections were lightly counterstained with Hematoxylin and examined by light microscopy. Our protocol was approved by the Institutional Animal Care and Use Committee at LifespanRhode Island Hospital, and it conforms to the guidelines set by the National Institutes of Health.

\section{Rotarod Testing}

We used rotarod testing to assess long-term effects of ICV si-InR, si-IGF-1R and si-IGF-2R treatments on motor function $[46,47]$. On P19, rats were trained to remain balanced on the rotating Rotamex -5 apparatus (Columbus Instruments) at 1-5 rpm. On P20, rats $(\mathrm{N}=$ 8-10 per group) were administered 10 trials at incremental speeds up to $10 \mathrm{rpm}$, with 10 minutes rest between each trial. The latency to fall was automatically detected and recorded with photocells placed over the rod. However, trials were stopped after 30 seconds to avoid exercise fatigue. Data from trials 1-3 (2-5 rpm), 4-7 (5-7 rpm), and 8-10 (8-10 rpm) were culled and analyzed using the Mann-Whitney test.

\section{Quantitative Reverse Transcriptase Polymerase Chain Reaction (qRT-PCR) Analysis}

We used qRT-PCR to measure mRNA expression as previously described [48-50]. In brief, cerebella were homogenized in Qiazol reagent, and total RNA was isolated using the EZ1 RNA universal tissue kit and the BIO Robot EZ1. RNA was reverse transcribed using random oligodeoxynucleotide primers and the AMV First Strand cDNA synthesis kit. The resulting cDNA templates were used in qPCR amplification reactions with gene specific primer pairs (Additional File 1) [51]. Primers were designed using MacVector 10 software (MacVector, Inc., Cary, NC) and their target specificities was verified using NCBI-BLAST (Basic Local Alignment Search Tool). The amplified signals were detected and analyzed using the Mastercycler ep realplex instrument and software (Eppendorf AG, Hamburg, Germany). Relative mRNA abundance was calculated from the ng ratios of specific mRNA to $18 \mathrm{~S}$ rRNA measured in the same samples. Assays were performed in triplicate. Inter-group statistical comparisons were made using the calculated mRNA/18S ratios.

\section{Enzyme Linked Immunosorbent Assay (ELISA)}

Cerebellar homogenates were prepared in radioimmunoprecipitation assay (RIPA) buffer containing protease and phosphatase inhibitors [50]. Protein concentrations were determined using the bicinchoninic (BCA) assay. We performed direct binding ELISAs to measure immunoreactivity. Samples containing 50 ng protein diluted in Tris buffered saline, pH 7.4 (TBS) were adsorbed to the bottom flat surfaces of 96-well polystyrene ELISA plates overnight at $4^{\circ} \mathrm{C}$ [44]. Non-specific binding sites were blocked by a 3-hour room temperature incubation with $300 \mu \mathrm{l} /$ well of TBS $+0.05 \%$ Tween $20+3 \%$ BSA. Samples were then incubated with $0.1-0.5 \mu \mathrm{g} / \mathrm{ml}$ primary antibody for $1 \mathrm{~h}$ at $37^{\circ} \mathrm{C}$. Immunoreactivity was detected with horseradish peroxidase (HRP)-conjugated secondary antibody and Amplex Red soluble fluorophore [44]. Fluorescence was measured (Ex 530/Em 590) in a SpectraMax M5 microplate reader. Parallel negative control assays had primary, secondary, or both antibodies omitted. Between steps, reactions were rinsed 3 times with TBS $+0.05 \%$ Tween 20 using a Nunc ELISA plate washer. Levels of immunoreactivity were normalized to protein content in the wells, which was measured using NanoOrange reagent.

\section{Statistical Analysis}

Data corresponding to levels of gene expression or immunoreactivity are depicted in boxplot graphs representing the means (horizontal bars), 95\% confidence intervals (box limits), and range (whiskers) for each group. Inter-group comparisons were made using the Kruskal-Wallis one-way Analysis of variance (ANOVA) with the Dunn's multiple comparisons post-hoc test of statistical significance. Statistical analyses were performed using the GraphPad Prism 5 software (San Diego, CA) and significant P-values $(<0.05)$ are indicated within the graph panels.

\section{Results}

ICV injection of si-RNA targeting the insulin or IGF receptors impairs motor performance

Rotarod tests are used to assess sensorimotor coordination and they provide a highly sensitive index of damage to the cerebellum $[46,52]$. Rotarod test results were 
analyzed by grouping performance for Trials 1-3, 4-6, and 7-10, in which the rotation speeds were incremented from 2 to $4.5,5$ to 7.5 , and 8 to $10 \mathrm{rpm}$, respectively. The mean \pm S.E.M. latency to fall periods were calculated and results are depicted graphically. In the two lower speed trial sets, all 4 groups performed similarly (Figures 1A-1B), whereas in the final and most challenging trial series, rotarod performance was significantly impaired in the si-InR, si-IGF-1R, and si-IGF-2R relative to si-Scr treated controls (Figure 1C).

\section{Cerebellar hypofoliation and hypotrophy following ICV injection of si-InR, si-IGF-1R, or si-IGF-2R}

Cerebella were harvested to examine histopathological effects of the ICV siRNA treatments, on P9 and P16 (Figure 2). Cerebella from si-Scr transfected controls had well-developed complex foliation with regular patterns of major deep and minor shallow grooving, slender white matter cores, compact and densely populated granule and Purkinje cell layers, and a uniform molecular layer (Figures 2A, 2E, 2I). In contrast, P9 brains, including cerebella from si-InR, si-IGF-1R, or si-IGF-2Rtransfected rats were smaller, and they had relatively simplified, shallow, blunted, and irregular folia, irregularly thickened white matter cores, and conspicuously hypocellular cortical granule cell layers relative to control (Figures 2B-2D, 2F-2H). The si-IGF-2R transfected rats had the most pronounced simplification and hypotrophy of cerebellar folia compared with all other groups (Figure 2). It is noteworthy that the Purkinje layer of cortex was consistently preserved, whereas the granule cell and molecular layers were variably affected by the si-RNA treatments. The relative sparing of Purkinje cells was most likely due to the fact that they develop in utero, while the granule and molecular layers develop mainly within the early postnatal period $[42,43,53]$ during which the ICV si-RNAs were delivered. At the later time point (P16), the effects of the siRNA treatments on cerebellar structure were subtler, but still manifested by relatively simplified and shallow foliation relative to control (Figures 2I-2L).

Adjacent histological sections were immunostained with monoclonal antibodies to HNE to assess levels of oxidative stress and lipid peroxidation, or AAH, which is a downstream target of insulin/IGF signaling and regulator of neuronal migration [44,45] (Additional File 2). Previous studies demonstrated that chronic in utero ethanol exposure increases HNE and reduces AAH immunoreactivity $[22,44,54]$. In the present study, si-Scr treated control cerebella had low levels of HNE
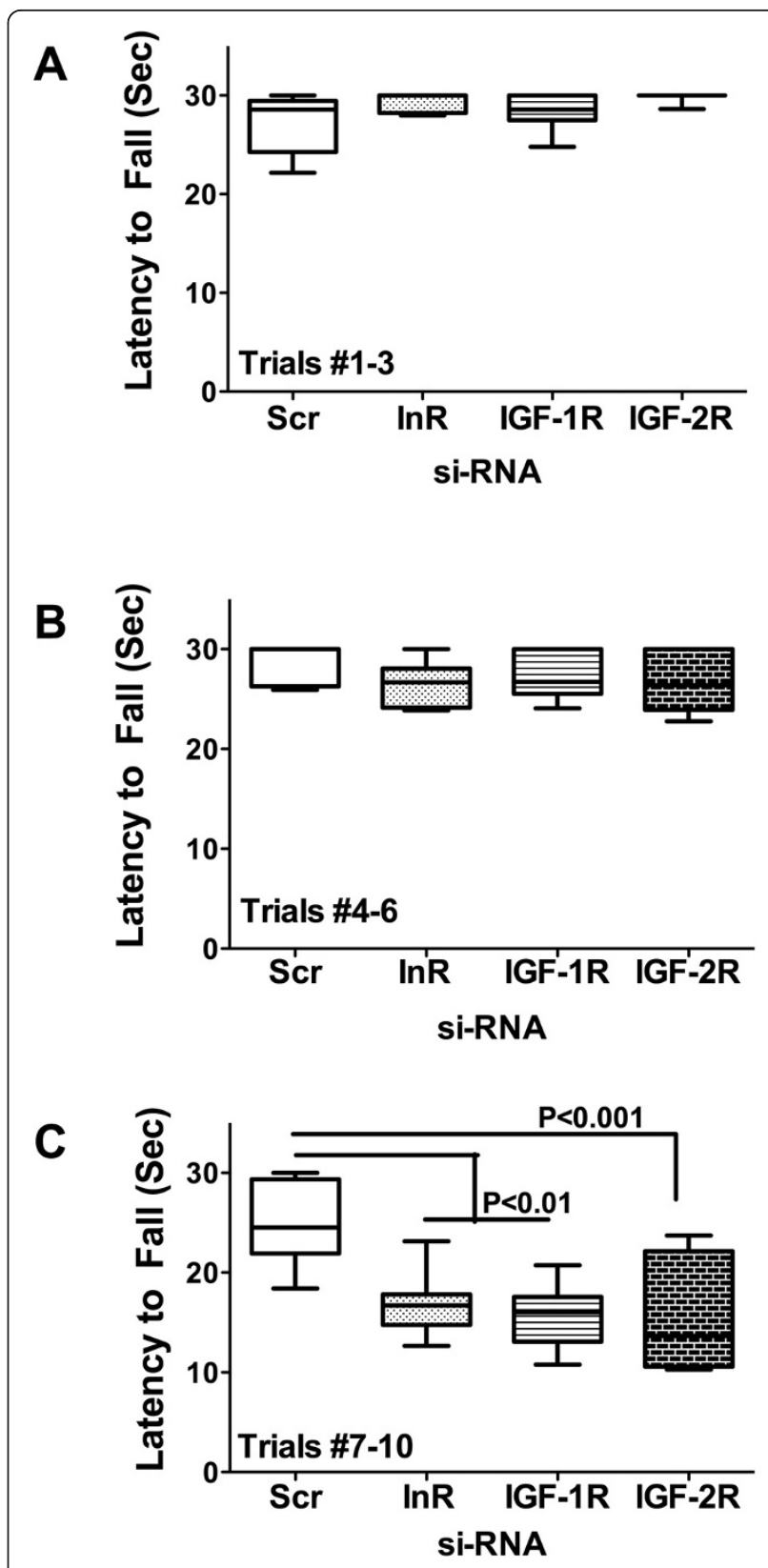

Figure 1 Effects of si-InR, si-IGF-1R, and si-IGF-2R ICV injections on motor performance. P2 Long Evans rat pups were administered intracerebroventricular (ICV) injections of si-RNA targeting the insulin receptor (InR), insulin-like growth factor type 1 receptor (IGF-1R), IGF-2R, or nonspecific sequences (Scr). On P20, rats were subjected to 10 incremental speed trials (from 2 to 10 rpm) of rotarod testing of motor function. Each trial was limited to 30 seconds duration. Data from (A) Trials 1-3 (2-4.5 rpm), (B) Trials 46 (5-7.5 rpm), and (C) Trials 7-10 (8-10 rpm) were culled and analyzed using the Mann-Whitney test. Panels display box plots with means (bar), 95\% confidence limits (box) and range (whiskers). Significant P-values are indicated within the panels. 


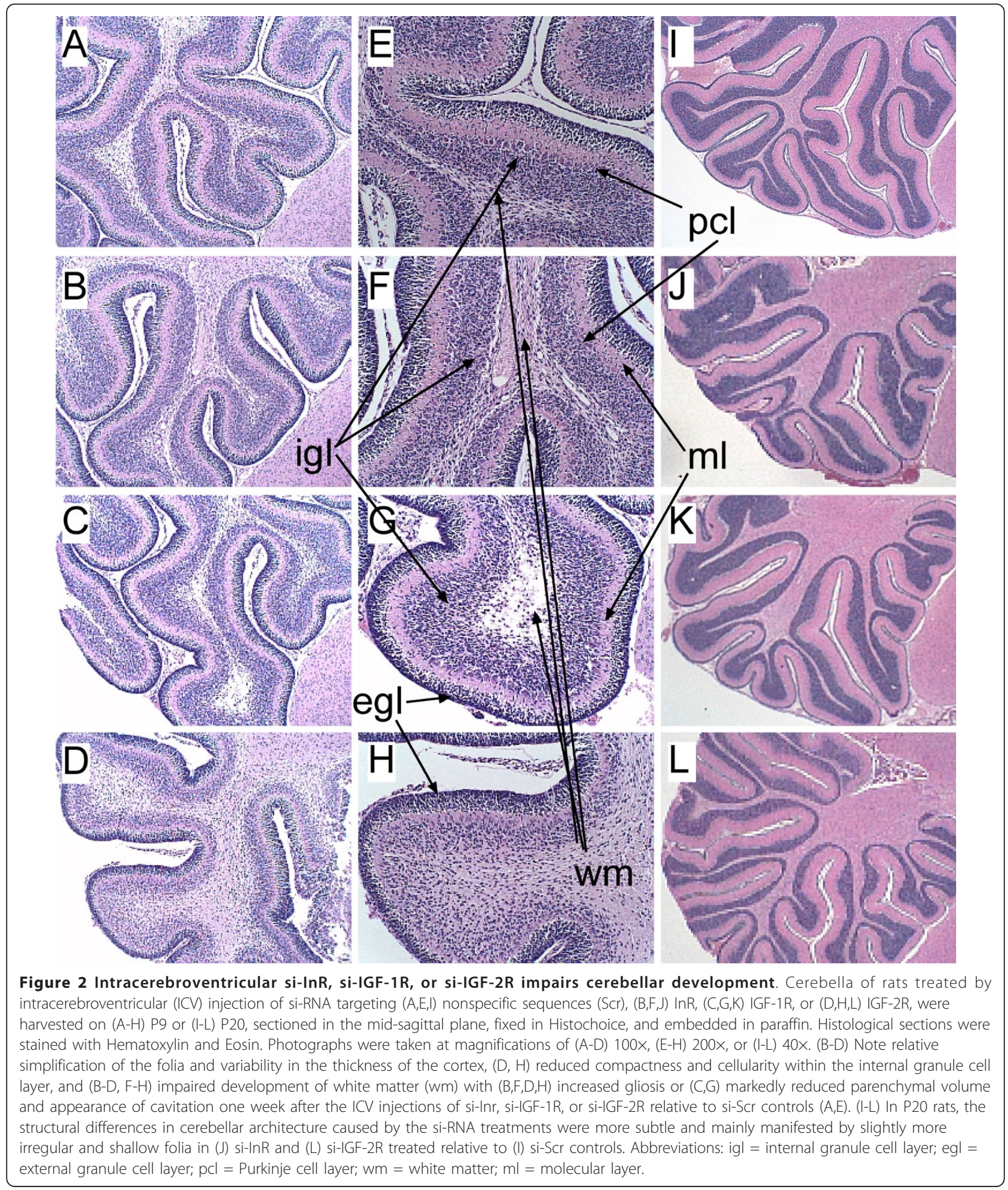


immunoreactivity, while cerebella exposed to specific siInR, si-IGF-1R, or si-IGF-2R had increased levels HNE immunoreactivity localized in the granule cell and Purkinje cell layers, as well as in white matter glia. ICV injection of si-IGF-2R increased HNE immunoreactivity to a greater extent than the other si-RNA treatments. The si-Scr treated control cerebella had abundant AAH immunoreactivity distributed in Purkinje and granule cells, as well as in neuropil fibrils. In contrast, ICV transfection with si-RNA targeting InR, IGF-1R, or IGF$2 \mathrm{R}$ was associated with lower levels of cerebellar AAH immunoreactivity relative to control. However, si-InR treatment resulted in increased AAH immunoreactivity in reactive, hypertrophic astrocytes distributed among granule cells.

\section{ICV injection of si-InR, si-IGF-1R, or si-IGF-2R inhibits cerebellar insulin, IGF-1, IGF-2 polypeptide and receptor gene expression}

ICV injection of si-InR significantly reduced the mean mRNA levels of insulin, insulin receptor, and IGF-1R relative to control. In addition, si-InR treated cerebella had significantly lower mean levels of IGF-1, IGF-2, insulin receptor, and IGF-1R relative to si-IGF-1R treated rats, and lower levels of IGF-2 compared with siIGF-2R treated rats (Figure 3 ). Rats treated by ICV injection of si-IGF-1R had significantly higher cerebellar levels of IGF-2 expression relative to control, higher levels of insulin, IGF-1, IGF-2, insulin receptor, and IGF-1R relative to si-InR treated rats, and higher levels of IGF-2R relative to si-IGF-2R treated rats. ICV injection of si-IGF-2R significantly reduced IGF-1R and IGF$2 \mathrm{R}$ expression relative to control.

\section{si-InR, si-IGF-1R, and si-IGF-2R alter neurotrophin and neurotrophin receptor expression in brain}

We used qRT-PCR analysis (Figure 4) and ELISAs (Figure 5) to measure expression of nerve growth factor, brain derived neurotrophic factor (BDNF), p75 and neuronal tyrosine (NRTK) kinase receptors in cerebellar tissue (Figure 4). The qRT-PCR studies demonstrated significantly lower mean levels of NGF in si-InR treated relative to si-IGF-1R and si-IGF-2R treated rats. Otherwise, the mRNA levels of BDNF, p75 and NRTK were similar among the groups. ELISA studies (Figure 5) revealed significant reductions in NT3 and BDNF neurotrophin immunoreactivity in si-InR and/or si-IGF-1R treated, but not si-IGF-2R treated cerebella relative to control. The mean levels of NGF were similar in the control and si-InR treated groups, but significantly elevated relative to control in si-IGF-1R and si-IGF-2R treated rats. The levels of NT3 immunoreactivity were similar in control and si-IGF-2R treated rats, but significantly reduced relative to control or si-IGF-2R in both
si-InR and si-IGF-1R treated rats. The mean levels of BDNF immunoreactivity were similar in control, si-InR, and si-IGF-1R treated rats, but significantly reduced in the si-IGF-1R treated relative to control rats. In contrast, no significant inter-group differences were observed with respect to NT4 expression.

\section{Inhibition of insulin or IGF receptors alters tau, pTau, ChAT, and GAPDH expression}

Brain insulin/IGF resistance is associated with accumulation of tau and phospho-tau, inhibition of cholinergic function, and impairments in energy metabolism $[22,24,41,54,55]$. ELISAs were used to measure tau, phospho-tau (pTau), ChAT, AChE, $\beta$-Actin, and GAPDH immunoreactivity (Figure 6). Both si-InR and si-IGF-1R significantly increased tau immunoreactivity, while si-InR significantly increased pTau, and si-IGF-1R significantly increased $\beta$-Actin. ICV delivery of si-InR, si-IGF-1R, and si-IGF-2R significantly reduced ChAT immunoreactivity relative to control, but did not significantly alter the mean levels of AChE immunoreactivity. Finally, si-InR, but not si-IGF-1R or si-IGF-2R ICV treatment reduced GAPDH expression in brain.

\section{Discussion}

Humans and experimental animals afflicted with FASD have sustained impairments in cognitive and motor functions. With regard to motor functions, the cerebellum is a major target of alcohol's neurotoxic and teratogenic effects during development. Phenotypic manifestations of FASD in the cerebellum include hypoplasia, hypofoliation, and disordered patterns of neuronal migration [15-21,56,57]. These effects of prenatal ethanol exposure are associated with impairments in neuronal growth, survival, motility, adhesiveness, energy metabolism, mitochondrial function, plasticity, and neurotransmitter function, and increased oxidative stress and DNA damage [22,25-27,42,54,58-67].

Ethanol mediates its adverse effects on CNS neurons through inhibition of insulin and insulin-like growth factor (IGF) signaling [34,68,69]. Ethanol impairs binding to the insulin/IGF receptors, preventing activation of receptor tyrosine kinases that transmit signals downstream through IRS molecules [22-28]. In addition, ethanol inhibits other kinases, and it activates phosphatases at various levels within the insulin/IGF signaling cascades $[27,70]$. The net result is to reduce the levels and duration of positive signaling. While these effects of ethanol support our hypothesis that several fundamental CNS abnormalities in FASD are attributable to impairments in insulin and IGF signaling, they do not exclude a role for neurotoxic injury caused by ethanol or its metabolites. In this regard, it is noteworthy that oxidative stress activates pro-inflammatory cytokines, which 

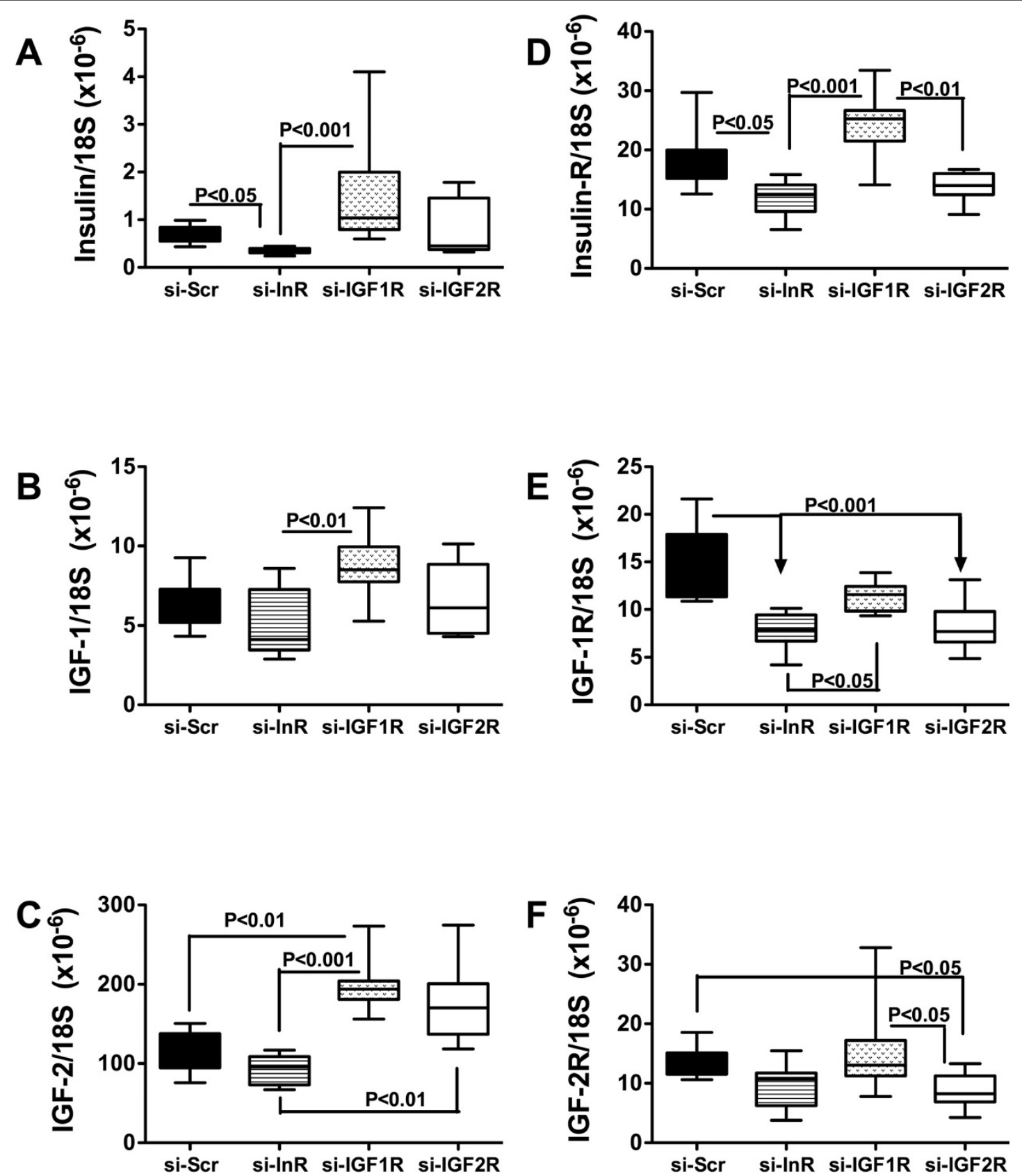

Figure 3 Inhibition of insulin and IGF signaling mechanisms in cerebella following ICV si-RNA delivery. Long Evans rat pups were administered ICV injections of si-Scr, si-InR, si-IGF-1R, or si-IGF-2R on P2. Cerebella harvested on P24 were used to measure (A) insulin, (B) IGF-1, (C) IGF-2, (D) insulin R, (E) IGF-1R, and (F) IGF-2R expression by qRT-PCR analysis with results normalized to $18 \mathrm{~S}$ rRNA. Box plots depict means, 95\% confidence intervals, and range for each group. Inter-group statistical comparisons were made using the Kruskal-Wallis one-way ANOVA and the Dunn's multiple comparisons post hoc test. Significant P-values are indicated within the panels.

promote cellular injury, DNA damage, mitochondrial dysfunction, cell death, and insulin resistance [24,25,31,32], while at the same time, insulin resistance promotes oxidative stress. The present study attempts clarify the contribution of reduced insulin and IGF signaling as a mediator of impaired cerebellar development and function as occur in FASD.
We used ICV injections to transfect immature brains with si-RNA duplex molecules targeting InR, IGF1R, IGF-2R, or nonspecific sequences (si-Scr). GFP expressing plasmid DNA was co-transfected in order to confirm success of the nucleic acid delivery. GFP expression, detected by qRT-PCR analysis, peaked within 2-3 days of gene delivery, and persisted throughout the period of 


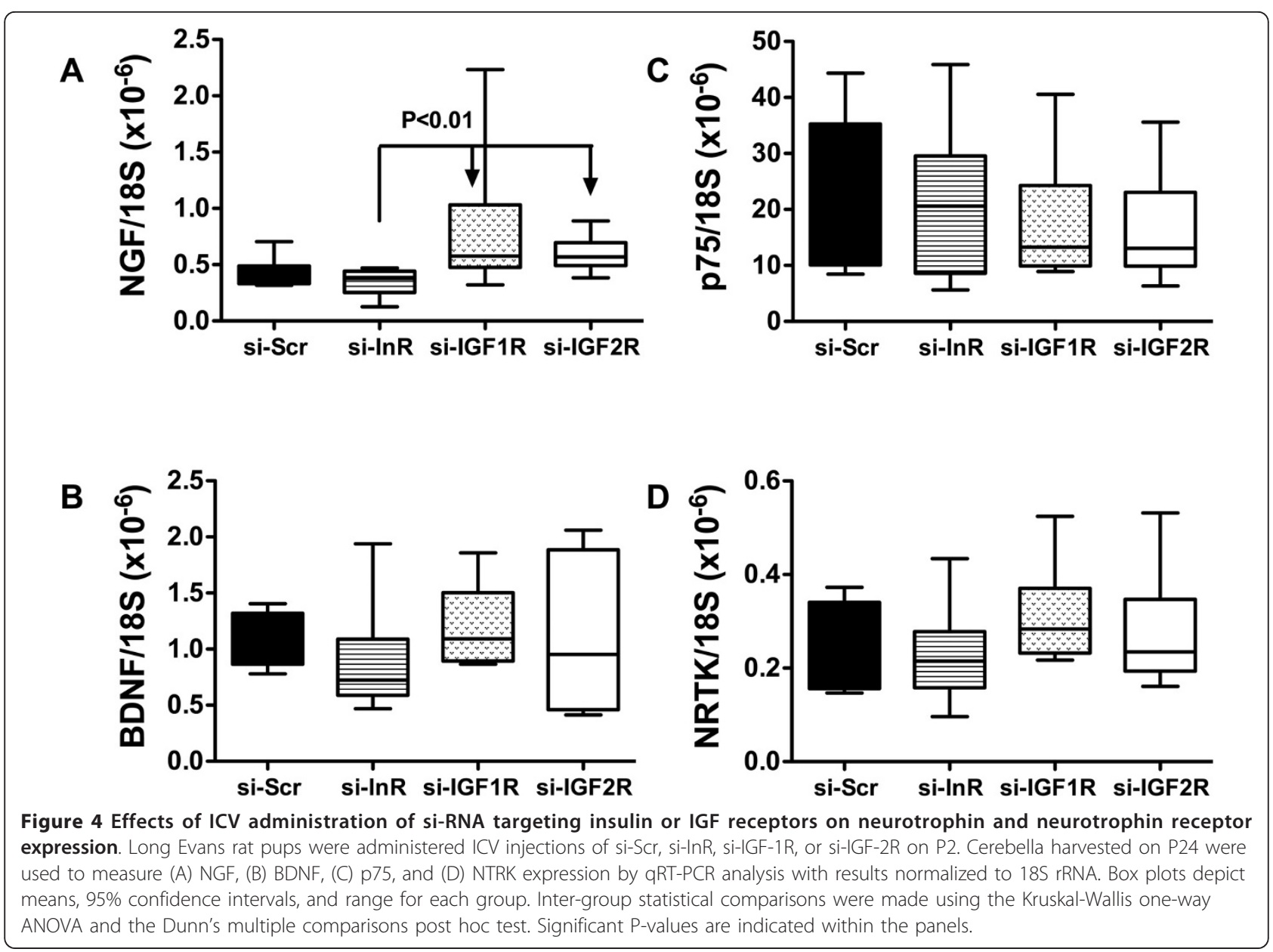

study. Previously, we used the same approach to generate a model of neurodegeneration, and demonstrated sustained transgene expression throughout the brain and in all cell types [39]. However, multiple attempts to generate similar models in adult brains proved unsuccessful. One limitation of this model is the inability to truly examine dose-effects since the method of gene suppression was transient and based on delivery of si-RNA molecules. On the other hand, an advantage of this approach is that the RNA duplexes do not persist in the brain, and therefore, any long-term effects could be attributed to transient targeted disruption of gene expression during a critical period of development. Although we did not include data from un-operated controls in this manuscript, the rotarod performance and brain structure in si-Scr transfected rats were comparable to previous findings in unoperated controls.

Rotarod tests performed nearly 2 weeks after the ICV injections revealed significant impairments in motor function in the si-InR, si-IGF-1R, and si-IGF-2R relative to si-Scr controls. Correspondingly, all 3 experimental groups had conspicuous abnormalities in cerebellar structure with hypotrophy, granule cell layer thinning with hypoplasia, and hypofoliation. In addition, the white matter cores were excessively thickened in si-InR and si-IGF-1R treated rats, and markedly attenuated in si-IGF-2R treated rats. Overall structural abnormalities in the cerebellum were most pronounced in si-IGF-2Rtreated rats, suggesting that signaling through the IGF$2 \mathrm{R}$ is critical for early postnatal cerebellar development. The finding that Purkinje cells were relatively spared corresponds with their earlier in utero development [43,53,71]. Granule cells and white matter fibers develop in the postnatal period when the si-RNA treatments were administered.

Quantitative RT-PCR analysis showed that si-InR broadly inhibited expression of insulin and IGF-2 polypeptides, and insulin, IGF-1, and IGF-2 receptors in brain. ELISA studies confirmed that the si-InR treatments inhibited expression of InR, IGF-1R, and IGF-2R. The si-IGF-2R treatments had similar but more restrictive inhibitory effects on insulin/IGF polypeptide and 


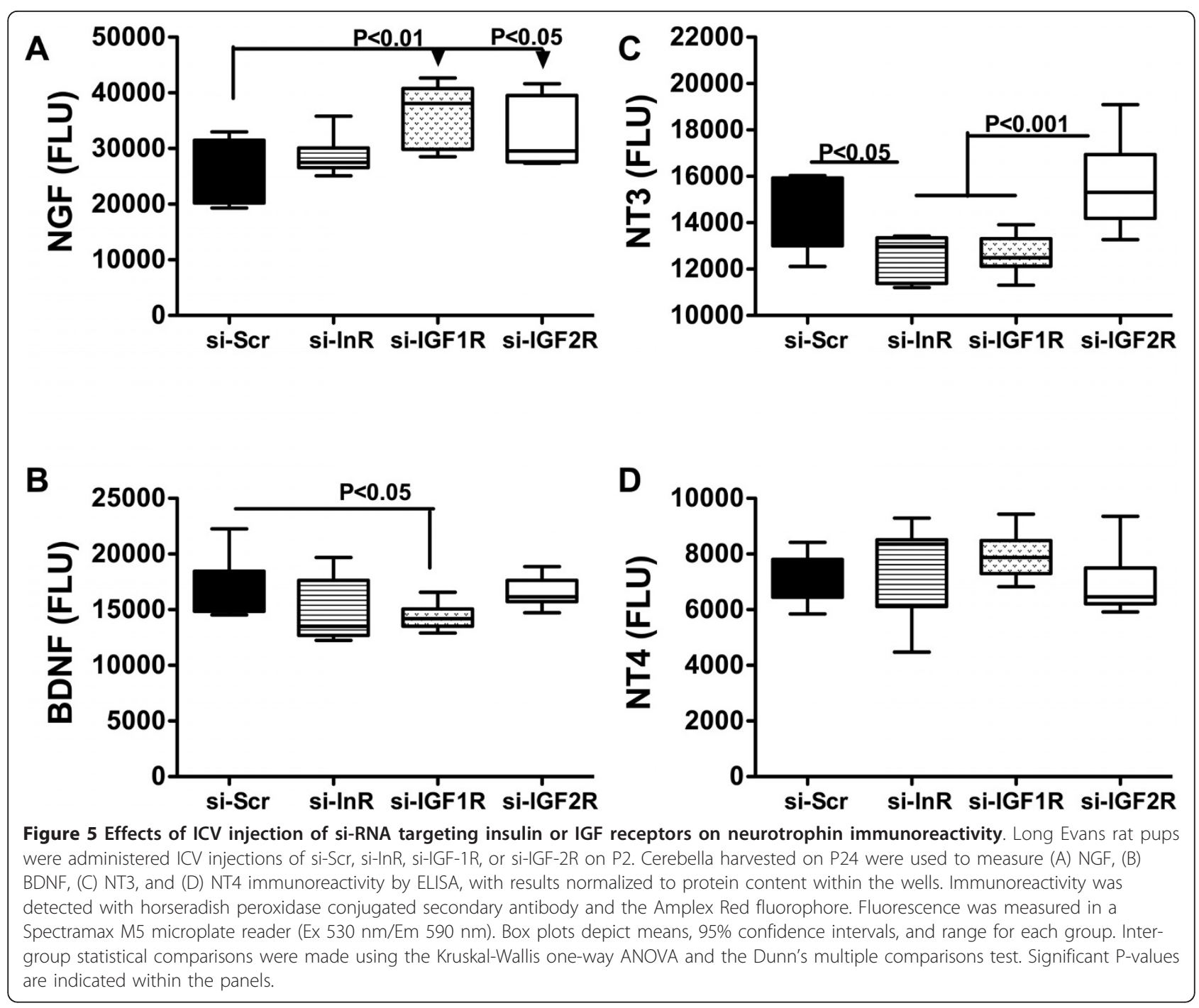

receptor expression in brain. These results suggest that InR is co-expressed with IGF-1R or IGF-2R and/or that insulin and IGF-2 polypeptides are expressed in InRand/or IGF-2R-positive cells. This overlap of signaling mechanisms suggests that these related receptors serve distinct functions during development, and the coexpression of trophic factors suggests the existence of either paracrine or autocrine stimulation networks. On the other hand, impaired signaling through InR, as occurs with ethanol exposure [22,72], reduces neuronal survival, energy metabolism, neurotransmitter function, particularly cholinergic, and mitochondrial function. The attendant increased apoptosis of InR-positive cells would likely reduce the population of IGF-1R- and IGF$2 \mathrm{R}$-bearing cells, and thereby decrease responsiveness to insulin, IGF-1 and IGF-2, since InR and IGF-1R or IGF$2 \mathrm{R}$ are likely co-expressed in developing cerebellar cells.
Reduced responsiveness to trophic factors would mimic effects of insulin/IGF resistance. In addition, since insulin and IGFs are expressed in InR, IGF-1R, and/or IGF-2Rbearing cells, trophic factor resistance and attendant cell loss would also lead to trophic factor deficiency. These points are relevant to FASD because ethanol exposure during development causes both insulin/IGF resistance and deficiency in cerebella and cerebellar granule neurons $[22,27]$. Moreover, the findings herein suggest that several characteristic structural and functional cerebellar abnormalities associated with FASD could be mediated by inhibition of signaling through the insulin and IGF receptors. Corresponding with observations in other models of brain insulin and IGF resistance, it may be possible to prevent or reduce the severity of ethanol-induced neurodevelopmental abnormalities with insulin sensitizer therapeutic agents such as peroxisome-proliferator 


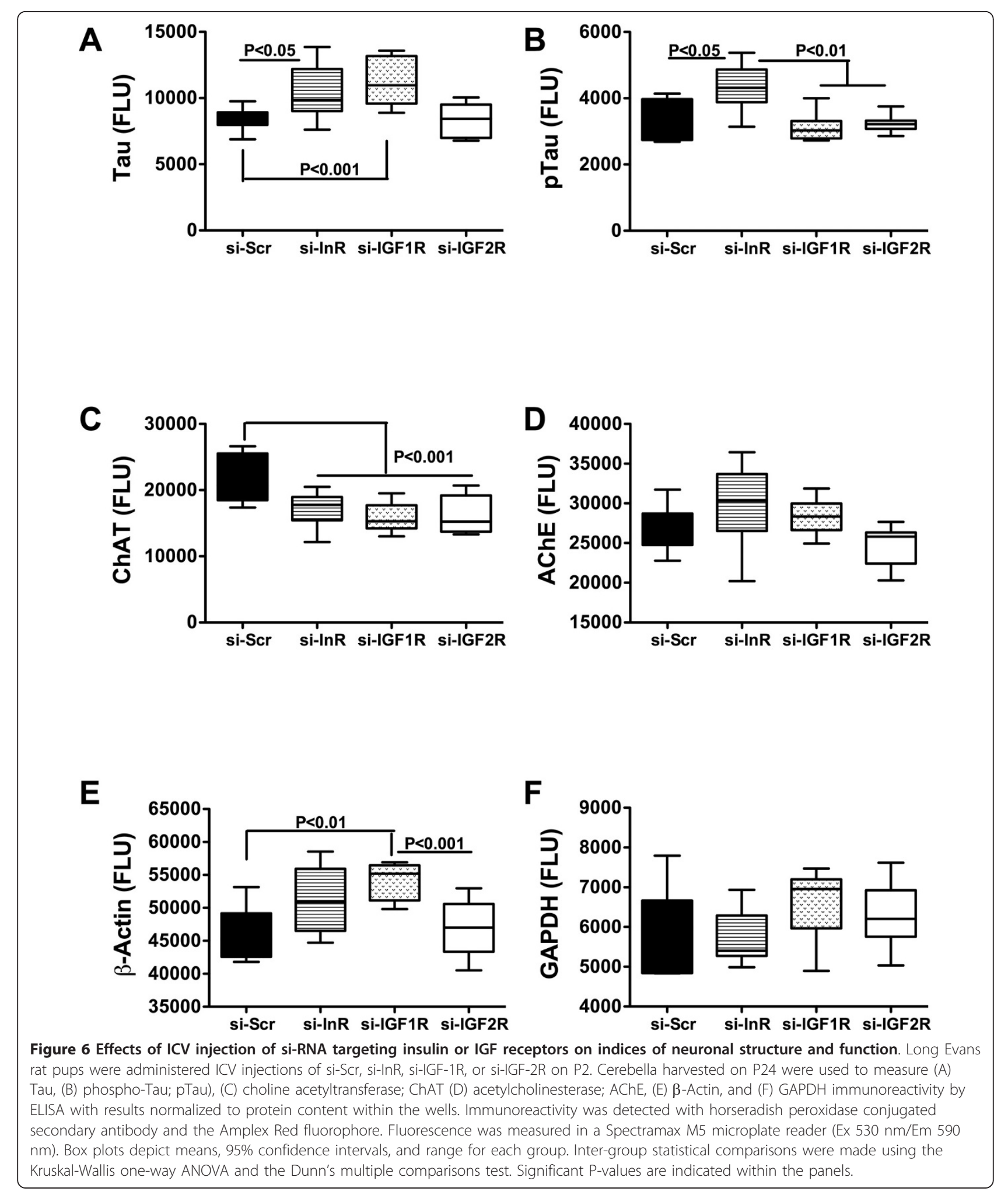


activated receptor agonists [73]. Recent preliminary studies suggest that this approach would be effective for restoring cerebellar function impaired by early postnatal ethanol exposure [41].

Consequences of impaired insulin and IGF signaling include inhibition of target gene expression and posttranslational modification of certain proteins. Insulin and IGF regulate expression of GAPDH [74], ChAT [75], and AAH [76]. Correspondingly, the studies herein demonstrated that siRNA targeting of InR, IGF-1R, or IGF-2R inhibited expression of all 3 proteins. In contrast, phospho-Tau, tau and $\beta$-actin levels were increased. si-InR, si-IGF-1R, and si-IGF-2R inhibition of GAPDH, which has an important role in energy metabolism, could account for the associated increased cerebellar levels of HNE. HNE, a marker of oxidative stress and lipid peroxidation, is also increased in brains afflicted with FASD and in neuronal cells exposed to ethanol in vitro [54]. ChAT, a major neurotransmitter that mediates motor function, is stimulated by insulin or IGFs, and correspondingly, ChAT expression was significantly reduced in brains transfected with si-InR, si-IGF$1 \mathrm{R}$, or si-IGF-2R. This effect could account for the significant impairments in Rotarod performance observed in all 3 experimental groups. In contrast to ChAT, neurotrophin and neurotrophin receptor expression were relatively spared by the si-RNA treatments, with the exceptions of NT3, which was inhibited by si-InR and si-IGF-1R, and BDNF, which was suppressed by si-IGF1R. Both BDNF and NT3 are inhibited by ethanol [61], and their expression and function are intimately tied to insulin and IGF signal transduction cascades [77,78].

ICV delivery of si-InR, si-IGF-1R, or si-IGF-2R reduced AAH immunoreactivity in cerebellar granule cells as demonstrated by immunohistochemical staining. AAH is another downstream target of insulin and IGF stimulation $[45,76]$ and a mediator of cell migration $[48,79]$. AAH promotes cell motility by interacting with, and hydroxylating Notch and its ligand, Jagged [80]. Notch signaling activates the transcription factors, HES and HEY [81,82], which modulate expression of target genes [83]. In FASD, impaired neuronal migration and cerebellar foliation correlate with insulin/IGF resistance and reduced AAH expression [44]. Since the si-RNA treatments mimicked these effects of FASD, it is likely that ethanol's inhibition of insulin/IGF signaling is sufficient to cause these teratogenic cerebellar abnormalities.

The increased cerebellar levels of phospho-tau in si-InR treated rats is explainable on the basis of relative insulin resistance since impaired insulin signaling leads to increased activation of kinases, including GSK-3 $\beta$, that promote tau phosphorylation [1]. High levels of phospho-tau can be neurotoxic and frequently are associated with neuronal injury, neurodegeneration, or oxidative stress $[50,69,84-87]$. On the other hand, increased levels of tau and $\beta$-actin immunoreactivity in si-InR and siIGF-1R treated rats, respectively suggest that impaired insulin and IGF-1 signaling may result in accumulation of cytoskeletal proteins. Although the consequences of these effects are unknown, they could promote oxidative stress and thereby contribute to the observed structural and functional abnormalities in the brain.

The relevance of these findings to FASD is that, both the ICV si-InR/IGF-R and developmental (prenatal or early postnatal) exposures to ethanol cause cerebellar hypoplasia with loss of cortical granule cells [22,27], disordered cell migration in the cerebellum [22,27], and impaired performance on rotarod testing [41]. In addition, reduced expression of InR/IGF-R is associated with reduced expression of insulin and IGF polypeptide genes, GAPDH, ChAT, and AAH $[22,27,44]$, and increased oxidative stress $[22,54]$ in cerebella of both the si-InR/IGF-R and prenatal ethanol exposure models. Although we have not yet published the effects of ethanol on tau expression and phosphorylation in the brain, a recent study by Saito, et al showed that early postnatal exposure to ethanol leads to increased phosphorylation, cleavage, and degradation of tau due to increased GSK-3 $\beta$ and caspase- 3 activation in the developing brain [88]. Of note is that similar mechanisms of AAH inhibition and degradation were also demonstrated in our model of FASD [45]. Therefore, the increased tau phosphorylation observed in cerebella of si-InR treated rats is also a feature of FASD. In contrast to our finding of increased $\beta$-actin immunoreactivity in cerebella of si-InR and si-IGF-1R treated rats, previous studies have demonstrated no significant effects of ethanol on $\beta$-actin expression [45], and instead showed that ethanol impairs cytoskeletal organization and adhesion mechanisms [89]. Altogether, the adverse effects of early postnatal ICV si-InR/IGF-R treatment on cerebellar development and function are similar to but less severe compared with FASD. The differences could be accounted for in part by the fact that both insulin and IGF receptors are impaired by ethanol, and that ethanol as well as acetaldehyde exert pronounced toxic and metabolic effects on immature neuronal cells [90].

\section{Conclusions}

The principal finding in this work were that molecular inhibition of the insulin or IGF receptors in the developing brain is sufficient to produce many of the effects associated with FASD in the cerebellum, including structural abnormalities, impaired motor function, altered expression of neurotrophins, neurotropin receptors, and genes and proteins that are regulated by insulin/IGF signaling, and increased oxidative stress. The more pronounced adverse effects of ethanol relative to ICV si-InR, si-IGF-1R, or si-IGF-2R could be attributed 
to broad-spectrum inhibition of these receptors and corresponding trophic factors, together with more pronounced oxidative injury mediated by the toxic effects of both ethanol and its chief metabolite, acetaldehyde.

\section{Additional material}

\section{Additional file 1: Primer pairs used for qRT-PCR assays. The table} includes primer pair sequences, primer binding positions on the mRNA and the amplicon (PCR product) sizes.

Additional file 2: Effects of si-RNA treatments on oxidative stress and AAH immunoreactivity. Figure depicting immunohistochemical staining for 4-hydroxy-2-nonenal and aspartyl-(asparaginyl)- $\beta$-hydroxylase (AAH) in cerebella of P16 rats that, on P2, were administered ICV injections of $(A, E)$ si-Scr, $(B, F)$ si-InR, $(C, G)$ si-IGF-1R, or $(D, H)$ si-IGF-2R. Paraffin-embedded histological sections of cerebella from P16 rats that were administered ICV injections of $(A, E)$ si-Scr, $(B, F)$ si-InR, $(C, G)$ si-IGF-1R, or $(D, H)$ si-IGF-2R on P2 were immunostained to detect (A-D) HNE as an index of oxidative stress and lipid peroxidation, or $(\mathrm{E}-\mathrm{H}) \mathrm{AAH}$, a gene regulated by insulin/IGF stimulation and a mediator of neuronal migration during development. Immunoreactivity was detected with HRP-conjugated polymer-linked secondary antibody and DAB as the chromogen (brown). Insets show higher magnification images of the granule cell/Purkinje cell layers. Note minimal HNE immunoreactivity in the si-Scr and si-IGF-1R treated brains, and increased labeling of both granule (small round nuclei) and Purkinje (pyramid or star-shaped) cells in the si-InR and si-IGF-2R treated brains. In contrast, AAH

immunoreactivity was robust in all cortical layers of si-Scr, si-InR, and siIGF-1R treated brains, and reduced in the granule cell layers of si-IGF-2R treated brains. In addition, in the si-InR treated brains, Purkinje cells exhibited intense AAH immunoreactivity (F). Original magnifications, 100x; insets, 400x.

\section{List of abbreviations}

AAH: aspartyl-(asparaginyl)- $\beta$-hydroxylase; AChE: acetylcholinesterase; ANOVA: analysis of variance; BCA: bicinchoninic assay; BDNF: brain-derived neurotrophic factor; ChAT: choline acetyltransferase; CNS: central nervous system; DAB: diaminobenzidine; ELISA: enzyme-linked immunosorbent assay; FASD: fetal alcohol spectrum disorder; GAPDH: glyceraldehyde-3-phosphate dehydrogenase; GFP: green fluorescent protein; H\&E: hematoxylin and eosin; HNE: 4-hydroxy-2-nonenal; HRP: horseradish peroxidase; ICV:

intracerebroventricular; IGF: insulin-like growth factor; IRS: insulin receptor substrate; NGF: nerve growth factor; NRTK: neuronal tyrosine kinase receptor; NT: neurotrophin; P: postnatal day; qRT-PCR: quantitative reverse transcriptase polymerase chain reaction; R: receptor; RIPA: radioimmunoprecipitation assay; Scr: scrambled; si: short-interfering; TBS: Tris buffered saline.

\section{Acknowledgements and funding}

The research was supported by grants AA-11431, AA-12908, and AAK2416126 from the National Institutes of Health.

\section{Author details}

${ }^{1}$ Department of Pathology and Division of Neuropathology, Rhode Island Hospital, 593 Eddy Street, Providence, RI 02903 USA. ${ }^{2}$ Department of Neurology, Rhode Island Hospital, 593 Eddy Street, Providence, RI 02903 USA. ${ }^{3}$ Department of Medicine and Division of Gastroenterology, Rhode Island Hospital, 593 Eddy Street, Providence, RI 02903 USA. ${ }^{4}$ Liver Research Center, 55 Claverick Street, Providence, RI 02903 USA. ${ }^{5}$ Alpert Medical School at Brown University, 97 Waterman Street, Providence, RI 02912 USA. ${ }^{6}$ Department of Biology, Brown University, 45 Prospect Street, Providence, RI 02912.

\section{Authors' contributions}

SMDLM conceived of, designed, and directed the research project, analyzed the data, and wrote the manuscript. MT performed most of the in vivo experiments and molecular studies. NB assisted with gene expression analysis and gene delivery experiments, and prepared draft portions of the manuscript. PM assisted with gene expression analysis and gene delivery experiments, and prepared draft portions of the manuscript. All authors have read and approved the final manuscript.

\section{Competing interests}

The authors declare that they have no competing interests.

Received: 27 December 2010 Accepted: 28 March 2011

Published: 28 March 2011

\section{References}

1. de la Monte SM, Wands JR: Review of insulin and insulin-like growth factor expression, signaling, and malfunction in the central nervous system: relevance to Alzheimer's disease. J Alzheimers Dis 2005, 7:45-61.

2. Chang L, Chiang SH, Saltiel AR: Insulin signaling and the regulation of glucose transport. Mol Med 2004, 10:65-71.

3. Giovannone B, Scaldaferri ML, Federici M, Porzio O, Lauro D, Fusco A, Sbraccia P, Borboni P, Lauro R, Sesti G: Insulin receptor substrate (IRS) transduction system: distinct and overlapping signaling potential. Diabetes Metab Res Rev 2000, 16:434-441.

4. Gammeltoft S, Fehlmann M, Van OE: Insulin receptors in the mammalian central nervous system: binding characteristics and subunit structure. Biochimie 1985, 67:1147-1153.

5. Hill JM, Lesniak MA, Pert CB, Roth J: Autoradiographic localization of insulin receptors in rat brain: prominence in olfactory and limbic areas. Neuroscience 1986, 17:1127-1138.

6. Broughton SK, Chen H, Riddle A, Kuhn SE, Nagalla S, Roberts CT Jr, Back SA: Large-scale generation of highly enriched neural stem-cell-derived oligodendroglial cultures: maturation-dependent differences in insulinlike growth factor-mediated signal transduction. I neurochem 2007, 100:628-638.

7. Freude S, Leeser U, Muller M, Hettich MM, Udelhoven M, Schilbach K, Tobe K, Kadowaki T, Kohler C, Schroder H, et al: IRS-2 branch of IGF-1 receptor signaling is essential for appropriate timing of myelination. J neurochem 2008, 107:907-917.

8. D'Ercole AJ, Ye P: Expanding the mind: insulin-like growth factor I and brain development. Endocrinology 2008, 149:5958-5962.

9. Chesik D, De Keyser J, Wilczak N: Insulin-like growth factor system regulates oligodendroglial cell behavior: therapeutic potential in CNS. Mol Neurosci 2008, 35:81-90.

10. Gong X, Xie Z, Zuo H: Invivo insulin deficiency as a potential etiology for demyelinating disease. Med Hypotheses 2008, 71:399-403.

11. Liang G, Cline GW, Macica CM: IGF-1 stimulates de novo fatty acid biosynthesis by Schwann cells during myelination. Glia 2007, 55:632-641.

12. Ye P, Kollias G, D'Ercole AJ: Insulin-like growth factor-I ameliorates demyelination induced by tumor necrosis factor-alpha in transgenic mice. J Neurosci Res 2007, 85:712-722.

13. Jones KL, Smith DW: Recognition of the fetal alcohol syndrome in early infancy. Lancet 1973, 2:999-1001.

14. Hanson JW, Jones KL, Smith DW: Fetal alcohol syndrome. Experience with 41 patients. Jama 1976, 235:1458-1460.

15. Clarren SK, Alvord EJ, Sumi SM, Streissguth AP, Smith DW: Brain malformations related to prenatal exposure to ethanol. J Pediatr 1978 92:64-67.

16. Clarren SK, Smith DW: The fetal alcohol syndrome. N Engl J Med 1978, 298:1063-1067.

17. Banakar MK, Kudlur NS, George S: Fetal alcohol spectrum disorder(FASD. Indian J Pediatr 2009, 76:1173-1175.

18. Nash K, Sheard E, Rovet J, Koren G: Understanding fetal alcohol spectrum disorders (FASDs): toward identification of a behavioral phenotype. ScientificWorldJournal 2008, 8:873-882.

19. Nayak RB, Murthy P: Fetal alcohol spectrum disorder. Indian Pediatr 2008 , 45:977-983.

20. Volk B: Cerebellar histogenesis and synaptic maturation following preand postnatal alcohol administration. An electron-microscopic investigation of the rat cerebellar cortex. Acta Neuropathol 1984, 63:57-65.

21. West JR, Dewey SL, Cassell MD: Prenatal ethanol exposure alters the postlesion reorganization (sprouting) of acetylcholinesterase staining in the dentate gyrus of adult rats. Brain Res 1984, 314:83-95. 
22. Soscia SJ, Tong M, Xu XJ, Cohen AC, Chu J, Wands JR, de la Monte SM: Chronic gestational exposure to ethanol causes insulin and IGF resistance and impairs acetylcholine homeostasis in the brain. Cell Mol Life Sci 2006, 63:2039-2056.

23. de la Monte SM, Ganju N, Tanaka S, Banerjee K, Karl PJ, Brown NV, Wands JR: Differential effects of ethanol on insulin-signaling through the insulin receptor substrate-1. Alcohol Clin Exp Res 1999, 23:770-777.

24. de la Monte SM, Neely TR, Cannon J, Wands JR: Ethanol impairs insulinstimulated mitochondrial function in cerebellar granule neurons. Cell Mol Life Sci 2001, 58:1950-1960.

25. de la Monte SM, Wands JR: Chronic gestational exposure to ethanol impairs insulin-stimulated survival and mitochondrial function in cerebellar neurons. CMLS, Cell Mol Life Sci 2002, 59:882-893.

26. de la Monte SM, Xu XJ, Wands JR: Ethanol inhibits insulin expression and actions in the developing brain. Cell Mol Life Sci 2005, 62:1131-1145.

27. Xu J, Yeon JE, Chang H, Tison G, Chen GJ, Wands J, de la Monte S: Ethanol impairs insulin-stimulated neuronal survival in the developing brain: role of PTEN phosphatase. J Biol Chem 2003, 278:26929-26937.

28. Ronis MJ, Wands JR, Badger TM, de la Monte SM, Lang CH, Calissendorff J: Alcohol-induced disruption of endocrine signaling. Alcohol Clin Exp Res 2007, 31:1269-1285.

29. Hallak H, Seiler AE, Green JS, Henderson A, Ross BN, Rubin R: Inhibition of insulin-like growth factor-I signaling by ethanol in neuronal cells. Alcohol Clin Exp Res 2001, 25:1058-1064

30. Zhong J, Deng J, Ghetti B, Lee WH: Inhibition of insulin-like growth factor I activity contributes to the premature apoptosis of cerebellar granule neuron in weaver mutant mice: in vitro analysis. J Neurosci Res 2002, 70:36-45.

31. Ramachandran V, Perez A, Chen J, Senthil D, Schenker S, Henderson GI: In utero ethanol exposure causes mitochondrial dysfunction, which can result in apoptotic cell death in fetal brain: a potential role for 4hydroxynonenal. Alcohol Clin Exp Res 2001, 25:862-871.

32. Zhang FX, Rubin $R$, Rooney TA: Ethanol induces apoptosis in cerebellar granule neurons by inhibiting insulin-like growth factor 1 signaling. J Neurochem 1998, 71:196-204.

33. Ikonomidou C, Bittigau P, Ishimaru MJ, Wozniak DF, Koch C, Genz K Price MT, Stefovska V, Horster F, Tenkova T, et al: Ethanol-induced apoptotic neurodegeneration and fetal alcohol syndrome. Science 2000, 287:1056-1060.

34. de la Monte SM, Longato L, Tong M, DeNucci S, Wands JR: The liver-brain axis of alcohol-mediated neurodegeneration: role of toxic lipids. Int $J$ Environ Res Public Health 2009, 6:2055-2075.

35. Deutsch SI, Urbano MR, Neumann SA, Burket JA, Katz E: Cholinergic abnormalities in autism: is there a rationale for selective nicotinic agonist interventions? Clin Neuropharmacol 2010, 33:114-120.

36. Pepeu G, Giovannini MG: Cholinesterase inhibitors and memory. Chem Biol Interact 2010, 187:403-408.

37. Dineley-Miller K, Patrick J: Gene transcripts for the nicotinic acetylcholine receptor subunit, beta4, are distributed in multiple areas of the rat central nervous system. Brain Res Mol Brain Res 1992, 16:339-344.

38. Peeyush KT, Savitha B, Sherin A, Anju TR, Jes P, Paulose CS: Cholinergic, dopaminergic and insulin receptors gene expression in the cerebellum of streptozotocin-induced diabetic rats: functional regulation with Vitamin D3 supplementation. Pharmacol Biochem Behav 2010, 95:216-222.

39. de la Monte SM, Jhaveri A, Maron BA, Wands JR: Nitric oxide synthase 3mediated neurodegeneration after intracerebral gene delivery. $J$ Neuropathol Exp Neurol 2007, 66:272-283.

40. Silbermann E, Moskal P, Bowling N, Tong M, de la Monte SM: Role of aspartyl-(asparaginyl)- beta-hydroxylase mediated Notch signaling in cerebellar development and function. Behavioral Brain Functions

41. de la Monte SM, Wands JR: Role of central nervous system insulin resistance in fetal alcohol spectrum disorders. J Popul Ther Clin Pharmacol 2010, 17:e390-e404.

42. Maier SE, Miller JA, Blackwell JM, West JR: Fetal alcohol exposure and temporal vulnerability: regional differences in cell loss as a function of the timing of binge-like alcohol exposure during brain development. Alcohol Clin Exp Res 1999, 23:726-734.

43. Maier SE, West JR: Regional differences in cell loss associated with bingelike alcohol exposure during the first two trimesters equivalent in the rat. Alcohol 2001, 23:49-57.
44. de la Monte SM, Tong M, Carlson Rl, Carter JJ, Longato L, Silbermann E, Wands JR: Ethanol inhibition of aspartyl-asparaginyl-beta-hydroxylase in fetal alcohol spectrum disorder: potential link to the impairments in central nervous system neuronal migration. Alcohol 2009, 43:225-240.

45. Carter JJ, Tong M, Silbermann E, Lahousse SA, Ding FF, Longato L, Roper N, Wands JR, de la Monte SM: Ethanol impaired neuronal migration is associated with reduced aspartyl-asparaginyl-beta-hydroxylase expression. Acta Neuropathol 2008, 116:303-315.

46. Goodlett CR, Thomas JD, West JR: Long-term deficits in cerebellar growth and rotarod performance of rats following "binge-like" alcohol exposure during the neonatal brain growth spurt. Neurotoxicol Teratol 1991, 13:69-74.

47. Kondo M, Gray LJ, Pelka GJ, Christodoulou J, Tam PP, Hannan AJ: Environmental enrichment ameliorates a motor coordination deficit in a mouse model of Rett syndrome-Mecp2 gene dosage effects and BDNF expression. Eur J Neurosci 2008, 27:3342-3350.

48. Cantarini MC, de la Monte SM, Pang M, Tong M, D'Errico A, Trevisani F, Wands JR: Aspartyl-asparagyl beta hydroxylase over-expression in human hepatoma is linked to activation of insulin-like growth factor and notch signaling mechanisms. Hepatology 2006, 44:446-457.

49. Gundogan F, Elwood G, Mark P, Feijoo A, Longato L, Tong M, de la Monte SM: Ethanol-induced oxidative stress and mitochondrial dysfunction in rat placenta: relevance to pregnancy loss. Alcohol Clin Exp Res 2010, 34:415-423.

50. Lester-Coll N, Rivera EJ, Soscia SJ, Doiron K, Wands JR, de la Monte SM: Intracerebral streptozotocin model of type 3 diabetes: relevance to sporadic Alzheimer's disease. J Alzheimers Dis 2006, 9:13-33.

51. Gundogan F, Elwood G, Longato L, Tong M, Feijoo A, Carlson RI, Wands JR, de la Monte SM: Impaired placentation in fetal alcohol syndrome. Placenta 2008, 29:148-157.

52. Heck DH, Zhao Y, Roy S, LeDoux MS, Reiter LT: Analysis of cerebellar function in Ube3a-deficient mice reveals novel genotype-specific behaviors. Hum Mol Genet 2008, 17:2181-2189.

53. Cragg B, Phillips S: Natural loss of Purkinje cells during development and increased loss with alcohol. Brain Res 1985, 325:151-160.

54. Chu J, Tong M, de la Monte SM: Chronic ethanol exposure causes mitochondrial dysfunction and oxidative stress in immature centra nervous system neurons. Acta Neuropathol 2007, 113:659-673.

55. de la Monte SM, Tong M, Cohen AC, Sheedy D, Harper C, Wands JR: Insulin and insulin-like growth factor resistance in alcoholic neurodegeneration. Alcohol Clin Exp Res 2008, 32:1630-1644.

56. Momino W, Sanseverino MT, Schuler-Faccini L: Prenatal alcohol exposure as a risk factor for dysfunctional behaviors: the role of the pediatrician. $J$ Pediatr (Rio J) 2008, 84:S76-79.

57. Thomas JD, La Fiette MH, Quinn VR, Riley EP: Neonatal choline supplementation ameliorates the effects of prenatal alcohol exposure on a discrimination learning task in rats. Neurotoxicol Teratol 2000, 22:703-711.

58. Swanson DJ, King MA, Walker DW, Heaton MB: Chronic prenatal ethanol exposure alters the normal ontogeny of choline acetyltransferase activity in the rat septohippocampal system. Alcohol Clin Exp Res 1995, 19:1252-1260.

59. Farr KL, Montano CY, Paxton LL, Savage DD: Prenatal ethanol exposure decreases hippocampal $3 \mathrm{H}$-vinylidene kainic acid binding in 45-day-old rats. Neurotoxicol Teratol 1988, 10:563-568.

60. Savage DD, Montano CY, Otero MA, Paxton LL: Prenatal ethanol exposure decreases hippocampal NMDA-sensitive [3H]- glutamate binding site density in 45-day-old rats. Alcohol 1991, 8:193-201.

61. Maier SE, Cramer JA, West JR, Sohrabji F: Alcohol exposure during the first two trimesters equivalent alters granule cell number and neurotrophin expression in the developing rat olfactory bulb. J Neurobiol 1999, 41:414-423.

62. Breese CR, D'Costa A, Sonntag WE: Effect of in utero ethanol exposure on the postnatal ontogeny of insulin-like growth factor-1, and type- 1 and type-2 insulin-like growth factor receptors in the rat brain. Neuroscience 1994, 63:579-589.

63. de la Monte SM, Ganju N, Banerjee K, Brown NV, Luong T, Wands JR: Partial rescue of ethanol-induced neuronal apoptosis by growth factor activation of phosphoinositol-3-kinase. Alcohol Clin Exp Res 2000, 24:716-726.

64. Resnicoff M, Rubini M, Baserga R, Rubin R: Ethanol inhibits insulin-like growth factor-1-mediated signalling and proliferation of $\mathrm{C} 6$ rat glioblastoma cells. Lab Invest 1994, 71:657-662. 
65. Olney JW, Ishimaru MJ, Bittigau P, Ikonomidou C: Ethanol-induced apoptotic neurodegeneration in the developing brain. Apoptosis 2000, 5:515-521.

66. Sari $Y$, Zhang $M$, Mechref $Y$ : Differential expression of proteins in fetal brains of alcohol-treated prenatally C57BL/6 mice: a proteomic investigation. Electrophoresis 2010, 31:483-496.

67. Miller MW, Dow-Edwards DL: Structural and metabolic alterations in rat cerebral cortex induced by prenatal exposure to ethanol. Brain Res 1988, 474:316-326.

68. de la Monte SM, Longato L, Tong M, Wands JR: Insulin resistance and neurodegeneration: roles of obesity, type 2 diabetes mellitus and nonalcoholic steatohepatitis. Curr Opin Investig Drugs 2009, 10:1049-1060.

69. de la Monte SM, Tong M: Mechanisms of nitrosamine-mediated neurodegeneration: potential relevance to sporadic Alzheimer's disease. J Alzheimers Dis 2009, 17:817-825.

70. Yeon JE, Califano S, Xu J, Wands JR, De La Monte SM: Potential role of PTEN phosphatase in ethanol-impaired survival signaling in the liver. Hepatology 2003, 38:703-714.

71. Ye $P$, Xing $Y$, Dai Z, D'Ercole AJ: In vivo actions of insulin-like growth factor-I (IGF-I) on cerebellum development in transgenic mice: evidence that IGF-I increases proliferation of granule cell progenitors. Brain Res Dev Brain Res 1996, 95:44-54.

72. Xu YY, Bhavani $K$, Wands JR, de la Monte SM: Ethanol inhibits insulin receptor substrate-1 tyrosine phosphorylation and insulin-stimulated neuronal thread protein gene expression. Biochem J 1995, 310:125-132.

73. de la Monte SM, Tong M, Lester-Coll N, Plater M Jr, Wands JR: Therapeutic rescue of neurodegeneration in experimental type 3 diabetes: relevance to Alzheimer's disease. J Alzheimers Dis 2006, 10:89-109.

74. Alexander BM, Dugast I, Ercolani L, Kong XF, Giere L, Nasrin N: Multiple insulin-responsive elements regulate transcription of the GAPDH gene. Adv Enzyme Regul 1992, 32:149-159.

75. Shi B, Rabin SJ, Brandoli C, Mocchetti I: Dexamethasone induces hypertrophy of developing medial septum cholinergic neurons: potential role of nerve growth factor. J Neurosci 1998, 18:9326-9334.

76. Lahousse SA, Carter JJ, Xu XJ, Wands JR, de la Monte SM: Differential growth factor regulation of aspartyl-(asparaginyl)-beta-hydroxylase family genes in SH-Sy5y human neuroblastoma cells. BMC Cell Biol 2006, 7:41.

77. Cowansage KK, LeDoux JE, Monfils MH: Brain-derived neurotrophic factor: a dynamic gatekeeper of neural plasticity. Curr Mol Pharmacol 2010, 3:12-29.

78. Maisonpierre PC, Belluscio L, Friedman B, Alderson RF, Wiegand SJ, Furth ME, Lindsay RM, Yancopoulos GD: NT-3, BDNF, and NGF in the developing rat nervous system: parallel as well as reciprocal patterns of expression. Neuron 1990, 5:501-509.

79. de la Monte SM, Tamaki S, Cantarini MC, Ince N, Wiedmann M, Carter J, Lahousse SA, Califano S, Maeda T, Ueno T, et al: Aspartyl-(asparaginyl)beta-hydroxylase regulates hepatocellular carcinoma invasiveness. J Hepatol 2006, 44:971-983.

80. Dinchuk JE, Focht RJ, Kelley JA, Henderson NL, Zolotarjova NI, Wynn R, Neff NT, Link J, Huber RM, Burn TC, et al: Absence of Post-translational Aspartyl beta -Hydroxylation of Epidermal Growth Factor Domains in Mice Leads to Developmental Defects and an Increased Incidence of Intestinal Neoplasia. J Biol Chem 2002, 277:12970-12977.

81. Hooper C, Tavassoli M, Chapple JP, Uwanogho D, Goodyear R, Melino G, Lovestone S, Killick R: TAp73 isoforms antagonize Notch signalling in $\mathrm{SH}$ SY5Y neuroblastomas and in primary neurones. J Neurochem 2006, 99:989-999.

82. Solecki DJ, Liu XL, Tomoda T, Fang Y, Hatten ME: Activated Notch2 signaling inhibits differentiation of cerebellar granule neuron precursors by maintaining proliferation. Neuron 2001, 31:557-568.

83. Katoh $M$, Katoh M: Integrative genomic analyses on HES/HEY family: Notch-independent HES1, HES3 transcription in undifferentiated ES cells, and Notch-dependent HES1, HES5, HEY1, HEY2, HEYL transcription in fetal tissues, adult tissues, or cancer. Int J Oncol 2007, 31:461-466.

84. Andersson C, Blennow K, Almkvist O, Andreasen N, Engfeldt $P$, Johansson SE, Lindau M, Eriksdotter-Jonhagen M: Increasing CSF phosphotau levels during cognitive decline and progression to dementia. Neurobiol Aging 2008, 29:1466-1473.

85. Avila J, Gomez de Barreda E, Engel T, Lucas JJ, Hernandez F: Tau phosphorylation in hippocampus results in toxic gain-of-function Biochem Soc Trans 2010, 38:977-980
86. Asuni AA, Perry VH, O'Connor V: Change in tau phosphorylation associated with neurodegeneration in the ME7 model of prion disease. Biochem Soc Trans 2010, 38:545-551

87. de la Monte SM, Ganju N, Feroz N, Luong T, Banerjee K, Cannon J, Wands JR: Oxygen free radical injury is sufficient to cause some Alzheimer-type molecular abnormalities in human CNS neuronal cells. $J$ Alz Dis 2000, 2:1-21.

88. Saito M, Chakraborty G, Mao RF, Paik SM, Vadasz C: Tau phosphorylation and cleavage in ethanol-induced neurodegeneration in the developing mouse brain. Neurochem Res 35:651-659.

89. Guasch RM, Tomas M, Minambres R, Valles S, Renau-Piqueras J, Guerri C: RhoA and lysophosphatidic acid are involved in the actin cytoskeleton reorganization of astrocytes exposed to ethanol. J Neurosci Res 2003, 72:487-502.

90. Tong M, Longato L, Nguyen QG, Chen W, Spaisman A, de la Monte SM: Acetaldehyde-mediated neurotoxicity: relevance to fetal alcohol spectrum disorders. Oxid Med Cell Longev .

doi:10.1186/1756-6606-4-13

Cite this article as: de la Monte et al.: si-RNA inhibition of brain insulin or insulin-like growth factor receptors causes developmental cerebellar abnormalities: relevance to fetal alcohol spectrum disorder. Molecular Brain 2011 4:13.

\section{Submit your next manuscript to BioMed Central and take full advantage of:}

- Convenient online submission

- Thorough peer review

- No space constraints or color figure charges

- Immediate publication on acceptance

- Inclusion in PubMed, CAS, Scopus and Google Scholar

- Research which is freely available for redistribution

Submit your manuscript at www.biomedcentral.com/submit
C Biomed Central 